\title{
Technology of three-dimensional laser scanning as a tool to provide safety for sport facilities
}

\author{
D.A. Gura1,2 (iD, D.A. Bespyatchuk1 (iD, S.V. Samarin ${ }^{1 *}$ (D) , N.M. Kiryunikova1 (iD, E.D. Lesovaya1 (iD \\ ${ }^{1}$ Kuban State Technological University, Krasnodar, Russia \\ ${ }^{2}$ Kuban State Agrarian University, Krasnodar, Russia \\ * Corresponding author: e-mail: sierghiei222@mail.ru
}

\begin{abstract}
Introduction. Human safety during sport activities depends mostly on the technical states of sport facilities. According to current legislation, every school and higher education institution with sport facilities must meet nationwide standards for safety requirements. Sports facilities with existing codes and GOSTR are inspected by a special committee, which is required for accreditation, and which has been applied for several decades. This study offers more accurate and up-to-date methods for inspection of these sport facilities, specifically three-dimensional laser scanning. The technology of three-dimensional laser scanning is used mainly to obtain high precision and detailed measurements of any object. The authors analyzed the methods of application of three-dimensional laser scanning to assure human safety during sport activities at schools and higher educational institutions. Materials and methods. The objects analyzed were running tracks at the stadium at Kuban State Technological University. The main research method is an empirical one, namely field measurements. Scanning of racetracks was performed with the Leica ScanStation C10 from six stations. After field measurements were taken, point cloud was imported into special software to process the results of the laser scanning by the Leica Cyclone. After measurements were taken, all the critical points of the racetracks were classified by the height. According to existing standards for racetracks at athletic stadiums, the allowable value of roughness is $10 \mathrm{~mm}$. Results and discussion. Classification of points revealed that the limit value for roughness of University's racetrack was $9 \mathrm{~mm}$ (which meets existing safety requirements for racetracks). Thus, racetracks of Kuban State Technological University underwent the accreditation process performed by the research group from the Department of Cadaster and Geo-Engineering. Conclusion. The conclusion of the paper detertmined that, in fact, laser scanning can be applied to control safety of race tracks.
\end{abstract}

KEY WORDS: safety of buildings and facilities, sport facility, monitoring and safety support for infrastructural facilities, threedimensional scanning, SDGs.

ACKNOWLEDGMENT: The research has been conducted under financial support provided by the Russian Fund of Fundamental Research and the Administration of Krasnodar Region of the Russian Federation within the framework of research project № 19-48-233020. Study of the possibility to use three-dimensional scanning to monitor and provide safety of infrastructural facilities in Krasnodar and Krasnodar region. The studies were carried out with the equipment of CCU "Research Center of Food and Chemical Technologies" KubSTU (CKP_3111).

FOR CITATION: Gura D.A., Bespyatchuk D.A., Samarin S.V., Kiryunikova N.M., Lesovaya E.D. Technology of three-dimensional laser scanning as a tool to provide safety for sport facilities. Nanotechnologies in Construction. 2021; 13(4): 259-263. Available from: doi: $10.15828 / 2075-8545-2021-13-4-259-263$.

\section{INTRODUCTION}

$\mathrm{P}$ hysical fitness is an activity aimed at strengthening human health and development of their physical abilities. It has been already proven that physical exercise harmonically develop body and allow improving health for many years to come. Physical fitness comprises a wide range of exercises and activities, starting from games and sports (football, basketball, volleyball, tennis) and ending with weightlifting. It is obvious that most physical exercises can cause injuries activities, and to participate successfully, physical well-being is needed. One should also note that an important role in the process of physical activity belongs to sport facilities at which a person does participate.

(c) Gura D.A., Bespyatchuk D.A., Samarin S.V., Kiryunikova N.M., Lesovaya E.D., 2021 
A sports facility is a special open or closed structure in which it is possible to hold training and competition of different sports etc. The quality and the state of such structures strongly affect the safety of a person when training as the negative condition may considerably rise the risk of being injured in a certain degree. Therefore, to monitor the state of such structures is of great importance.

One should mark, the course "Physical Fitness" is an obligatory discipline at schools and higher educational institutions in many countries, including Russia. Today there are about forty thousand schools and seven hundred forty-two universities in our country. According to the Construction Code 278.1325800.2016 "Buildings of higher educational organization. Design codes" and Construction Code 251.1325800.2016 "Buildings of regular educational organizations. Design codes" every higher educational institution and every school must be equipped with sport structures which are safe for physical training. Unfortunately, some of educational institutions, especially schools, take responsibility lightly with respect to these requirements, a fact is proven by the following statistics: in 2020 about $20 \%$ of all Russian schools and their facilities need to be renovated. At this, $1.5 \%$ of schools in Russia need major repairs, including their sport facilities [3].

As for higher educational institutions, according to Federal State Statistic Service's data, the condition of almost all sport facilities at universities is sub-standard. Safety of these facilities must be considered as the students' exercises, when doing sport, are more complex than those of school pupils.

At present, a special committee performs inspection of sport facilities in Russia. Such inspection is periodic and takes place once every several years. For several decades, this approach has been obligatory and a constant method for accreditation of sport objects. This study proposes another, more accurate method to control safety of sport facilities: three-dimensional laser scanning.

Three-dimensional laser scanning is a fieldwork system which measures with high accuracy distances, vertical and horizontal angles. The result of three-dimensional laser scanning is a point cloud, using which different objects are rendered [7]. Three-dimensional laser scanning by the type of applied equipment is classified into three classes: air, which is performed mainly with drone aircraft, ground and mobile $[1-2,6]$. Three-dimensional laser scanning is employed in many fields of human activities and quite often is used in:

- Monitoring of deformations in buildings and structures;

- Geotechnical surveys;

- Survey tracking of drill and explosive works;

- Recording of car accidents, crime sites, etc. [9-11].

Laser scanners are also used in construction of sport facilities and structures, but the present work studies the perspective on the potential of applying laser scanners to monitor the state of racetracks at the athletic stadiums [4-8].

The scope of the study is to analyze the perspective on the potential of applying three-dimensional laser scanning in monitoring to check the state of race tracks at the athletic stadiums.

The tasks of the study:

1. Based on statistic data to analyze the safety level of sport facilities situated at the territory of educational organizations.

2. To investigate existing method of accreditation of sport facilities.

3. To apply laser scanning to a certain sport facility to reveal compliance or incompliance of the given facility characteristics with existing safety codes valid for sport facilities.

4. To make conclusions on the potential of applying three-dimensional laser scanning to provide safety for sport facilities.

\section{METHODS AND MATERIALS}

To inspect safety of racetracks, the athletic stadium of Kuban State Technological University (KubSTU), which location is Krasnodar, Moskovskaya str., bld. 2, has been chosen. The photography of it is in Fig. 1.

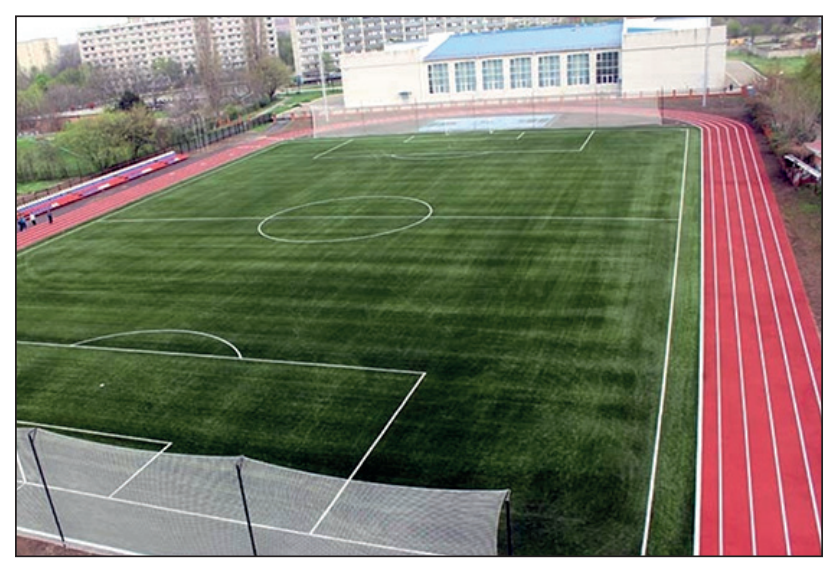

Fig. 1. The athletic stadium of Kuban State Technological University

Scanning was performed with the laser scanner Leica ScanStation C10. The photography of the scanner is in Fig. 2.

The research group set following parameters when scanning athletic stadium of Kuban State Technological University: discretion 10x10 cm, exposure time $64 \mathrm{sec}$, resolution 1920x1920 pixels, scanning coverage was $360 \times 270^{\circ}$, scanning process ran from 6 stations. After scanning, point cloud was imported into special software Leica Cyclone to render objects. 


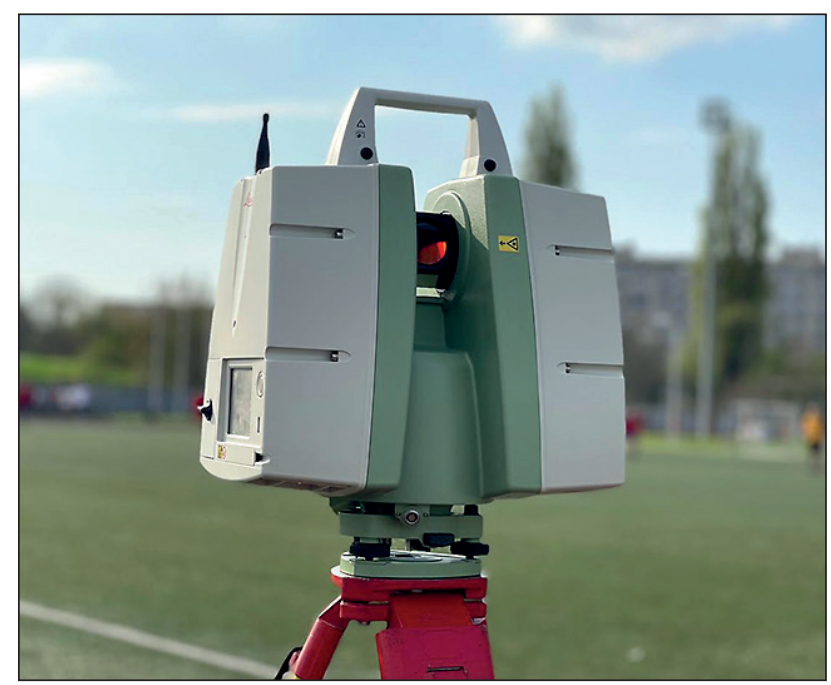

Fig. 2. Laser scanner Leica ScanStation C10

\section{RESULTS AND DISCUSSION}

Rendered stadium in software Leica Cyclone is in Fig. 3.

Having rendered the stadium, the points of racetrack were classified by height. Each height value was assigned color. An array of points with colors corresponding to their height is presented in Fig. 4.

One should note that colors correspond to the following height values:

- green $-0-2 \mathrm{~mm}$;

- blue $-2-3 \mathrm{~mm}$;

- yellow $-3-5 \mathrm{~mm}$;

- orange $-5-7 \mathrm{~mm}$;

- red $-7-8 \mathrm{~mm}$

- black - 8-9 mm.

According to GOST R 55529-2013 «Sport facilities. Requirements to safety during sport and training activities.
Fig. 3. Point cloud Processed in software Leica Cyclone

Fig. 4. Rendered cloud, which points were classified by the height in software Leica Cyclone
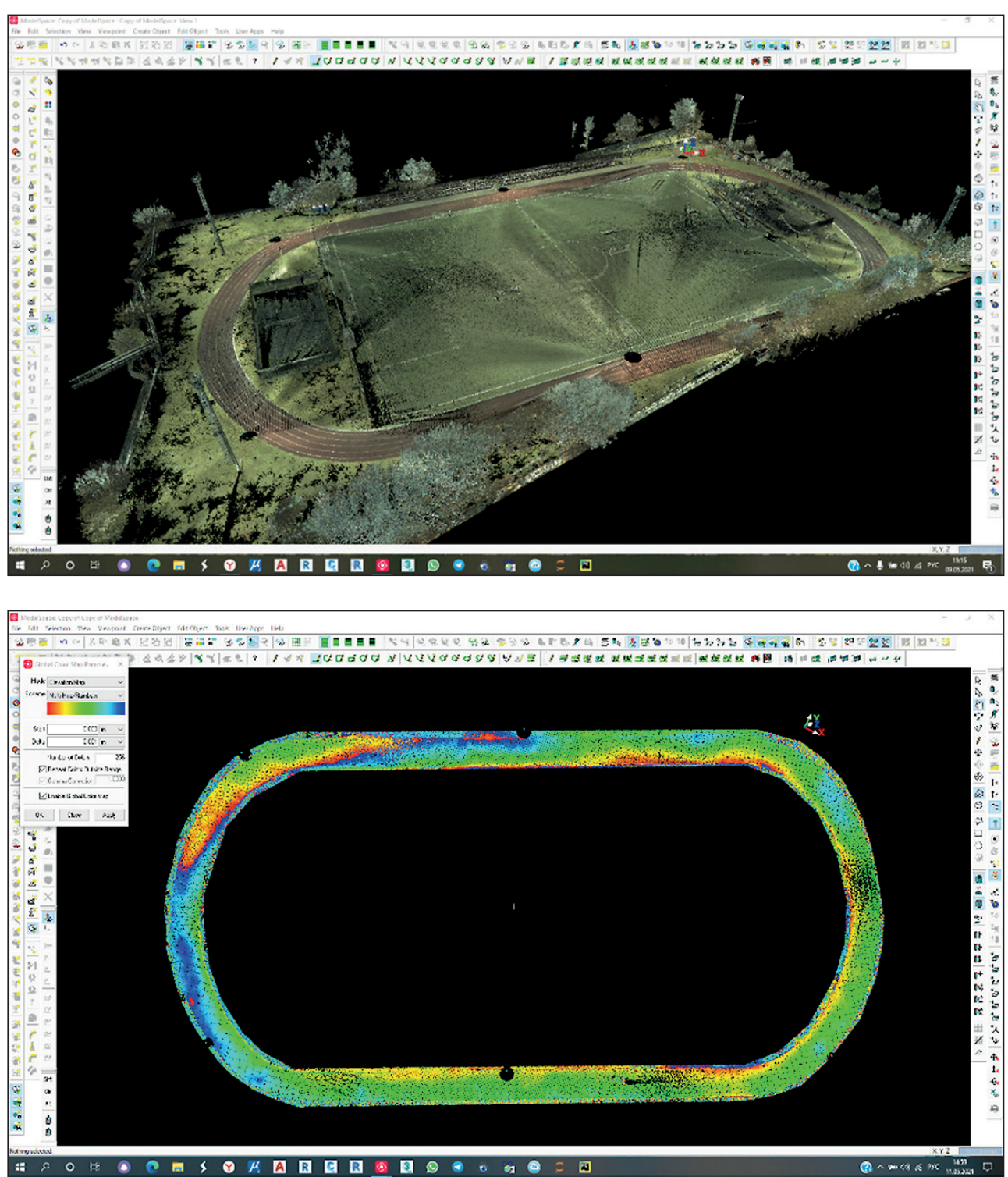
Table 1

Comparison of scanning results and requirements of GOST R 55529-2013

\begin{tabular}{|l|c|c|}
\hline \multicolumn{1}{|c|}{ Point colour } & Value of roughness, $\mathbf{m m}$ & $\begin{array}{c}\text { If the requirements } \\
\text { of GOST R 55529-2013 were met }\end{array}$ \\
\hline Green & $0-2$ & YES \\
\hline Blue & $2-3$ & YES \\
\hline Yellow & $3-5$ & YES \\
\hline Orange & $5-7$ & YES \\
\hline Red & $7-8$ & YES \\
\hline Black & $8-9$ & YES \\
\hline
\end{tabular}

Testing methods», the value of roughness on racetracks must not exceed $10 \mathrm{~mm}$. Comparison of the scanning results and mentioned above code is presented in the table 1.

On the basis of information obtained in analysis of scanning results and requirements of the mentioned above code (table 1), one can conclude that the values of roughness found at the KubSTU's stadium meet requirements of GOST R 55529-2013, and thus, this sport facility is considered to be safe for doing physical exercises.

\section{CONCLUSION}

This study found that the method used to analyze the state of sport facilities by means of three-dimensional scanning is rather promising and efficient. Scanning makes it possible to perform area survey for different objects with significant rate and to perform huge measurements with high accuracy and descriptiveness within a short time.

This paper considered application of ground laser scanning system as one of the methods to monitor deformations and to control the state of sport facilities; the process to perform field survey at KubSTU's athletic stadium (as an example) in Krasnodar and processing of data of three-dimensional laser scanning in a special software.

In conclusion, one can mark some advantages of ground laser scanning system:

1. Instant three-dimensional visualization.

2. The technology of work process is easy to understand.

3. High accuracy.

4. Fast data accumulation.

5. Detection of deformations at early stages of object operation.

6. Descriptiveness [9].

The costs of materials used in data collection and modelling of infrastructural objects by means of ground laser scanning in small areas and objects are much higher than those of traditional survey methods. Today the advantages of laser scanning allow avoiding additional expenditures during design and operation stages [10, 11]. Moreover, due to constant technical progress the cost of scanning equipment is expected to decrease, that in near future will make it more applicable even for infrastructural objects of less value.

\section{REFERENCES}

1. Gura D.A, Dubenko V.Yu., Buchatsky P.Yu., Markovsky I.G., Husht N.I. Monitoring of complex infrastructure facilities. The Bulletin of the Adyghe State University. The series "Technical Sciences". 2019; 4(251): 74-80.

2. Hashpakyanz N.O., Gribkova I.S. Application of laser scanning in land utilization and cadastre. Scientific works of the Kuban State Technological University. 2017; 9: 27-35.

3. Gura D., Samarin S., Bespiatchuk D., Khusht N., Pshidatok S. Sustainable development of society and a city based on safe infrastructure facilities. In: E3S Web of Conferences: 1, Yekaterinburg, 28-29 September 2020, Yekaterinburg. 2020. p. 06018. Available from: doi: 10.1051/e3sconf/202020806018.

4. Koch C., Georgieva K., Kasireddy V., Akinci B., Fieguth P. A review on computer vision based defect detection and condition assessment of concrete and asphalt civil infrastructure. Advanced Engineering Informatics. 2015; 29(2): 196-210. 
5. Emelyanov M.V. Information technology to design monitoring systems for buildings and facilities. The Bulletin of the Dagestan State University. The series "Technical Sciences”. 2019; 46(1): 123-131.

6. Diachenko R.A., Gura D.A., Bespyatchuk D.A., Samarin S.V., Kosolapov P.A. Analysis of software for evaluation of laser scanning results In: Scientific readings named after professor Zhukovsky N.E.: Proceedings of scientific papers of the XI International Scientific and Practical Conference. Krasnodar, 23-24 December 2020. Krasnodar: LLC "Publishing House - Yug", 2021. p. 485-493.

7. Gura D., Husht N., Markovsky I. The principles of monitoring for transport facilities. Krasnodar: Kuban State Technological University, 2021.

8. Gura D.A., Kiryunikova N.M., Lesovaya E.D., Husht N.I., Pavlyukova A.P. A system to monitor state of infrastructural facilities. The Bulletin of the Dagestan State University. The series "Technical Sciences". 2020; 47(3): $49-59$.

9. Sidorenko Yu.A., Tsvetkova N.Yu. The problems of monitoring of transport facilities state. Interactive Science. 2016; 2: 151-154.

10. Deryugin P.V., Bogacheva L.A. The perspective development of the systems aimed at diagnostics, monitoring and service for transport facilities. In: Proceedings of the IV International Student Scientific and Practical Conference. 2016; 14-16.

11. Gribkova I.S., Lesovaya E.D., Kiryunikova N.M., Tyupenkova G.E., Gura D.A. Geoinformation systems as an aspect of providing conditions for barrierless tourism and adaptive sport activities for disabled people. Adaptive Physical Culture. 2020; 84(4): 44-47.

\section{INFORMATION ABOUT THE AUTHORS}

Dmitry A. Gura, Assistant Professor of Cadastre and Geoengineering Department, Kuban State Technological University; Assistant Professor of Geodesy Department, Kuban State Agrarian University; Krasnodar, Russia,

ORCID: https://orcid.org/0000-0002-2748-9622, e-mail: gda-kuban@mail.ru

Daria A. Bespyatchuk, Training Master of Cadastre and Geoengineering Department, Kuban State Technological University, Krasnodar, Russia, ORCID: https://orcid.org/0000-0001-6711-385X, e-mail: dbespyatchuk99@mail.ru

Sergey V. Samarin, Training Master of Cadastre and Geoengineering Department, Kuban State Technological University, Krasnodar, Russia, ORCID: https://orcid.org/0000-0001-5431-7351, e-mail: sierghiei222@mail.ru

Nadezhda M. Kiryunikova, Engineer of Cadastre and Geoengineering Department, Kuban State Technological University, Krasnodar, Russia, ORCID: https://orcid.org/0000-0002-8020-768X, e-mail: kiryunikovaa2001@yandex.ru

Elina D. Lesovaya, Engineer of Cadastre and Geoengineering Department, Kuban State Technological University, Krasnodar, Russia, ORCID: https://orcid.org/0000-0002-4383-4828, e-mail: elyaaa_I29102000@mail.ru

\section{Authors declare the absence of any competing interests.}

Received: 29.06.2021.

Revised: 21.07.2021.

Accepted: 23.07.2021. 